\title{
EDUCACION PREESCOLAR: LA DEFINICION SOCIAL DE LA PRIMERA NIÑEZ*
}

María Cristina Salazar

\section{La definición social de la primera niñez}

Una condición preliminar al análisis de las funciones de la educación preescolar es la de conocer las definiciones sociales que se dan del niño en sus primeros años, en las distintas instituciones, en las teorías y prácticas pedagógicas corrientes, y en los sistemas de relaciones existentes entre los diversos "agentes" que tienen que ver con la educación pre-escolar. En este estudio se partió de la hipótesis de que existen nuevas y diferentes definiciones sociales de la primera niñez. Por lo tanto, parecía importante descubrirlas y relacionarlas con una definición social dominante, como una condición necesaria para poder llevar a cabo el análisis de los usos y funciones de los sistemas pre-escolares, y evidentemente para sugerir cambios en los mismos.

Para iniciar la investigación, se partió de una definición de la primera infancia, corriente en la escuela francesa, que incluye dos elementos esenciales: la ingenuidad del niño y su espontaneidad en el aprendizaje y en el desarrollo de sus capacidades ${ }^{82}$. Estas son características socialmente construidas, moldeadas a través de un proceso histórico, que permiten formas sutiles de tratar y, en verdad, de "manejar" al grupo de niños menores de 7 años. La definición incluye el concepto del niño como aprendiz inteligente y creativo artísticamente. Se descubre al niño como "sujeto cultural", hecho relacionado con condiciones culturales específicas, en especial con el desarrollo y difusión del conocimiento sicológico entre capas más amplias de la población.

Distintos sicólogos han señalado la importancia de este período para la formación de la personalidad del niño, particularmente para el desarrollo de la inteligencia. La divulgación de este conocimiento contribuye al cambio que ocurre en la definición social de la niñez: ya no se trata de definir la infancia del niño en términos de éste como sujeto a quien debe cuidarse fisiológicamente, sino que la primera niñez se convierte en un período que demanda también cuidados educacionales y sicológicos especiales. Ejemplo de ello son la multiplicación de los centros pre-escolares y el surgimiento de la industria de juguetes culturales y educativos, libros para niños cada vez de menor edad, discos y juegos diversos.

Este nuevo énfasis intelectual se ha ido combinando poco a poco con aspectos relacionados con la evolución del arte. Ocurre una convergencia entre la forma como la sociedad define a la primera niñez (obviamente según su estructura de clases), y la evolución teórica y pedagógica basada en una renovación de diversas disciplinas y, particularmente, en la génesis de las funciones intelectuales. Antes del "descubrimiento" de la inteligencia del niño y de los estudios de Piaget, el entrenamiento intelectual se definía principalmente como el desarrollo de la observación y la curiosidad -recuérdense los escritos de María Montessori y Decroly al respecto. El niño no iba a la escuela propiamente para ser enseñado, sino para aprender a observar, escuchar y hablar. Se

\footnotetext{
* El presente artículo se basa en una investigación actualmente en curso sobre educación pre-escolar en Bogotá, llevada a cabo bajo el auspicio de la Universidad Nacional de Colombia. El enfoque de la investigación es etnográfico y participativo y se hace énfasis en los aspectos cualitativos de la información.

${ }^{* *}$ Socióloga. Profesora asociada, Universidad Nacional de Colombia. Participó en esta investigación Pettina Reis, socióloga.

${ }^{82}$ Chamboredon, J. C. y J. Prévot, Changes tn the social Definition of childhood. Theory and Soclety, III, 2: 331-350. 1975.
} 
actuaba sobre la premisa de que las ideas penetrarían lentamente en las jóvenes mentes por medio de los ojos y los oídos. La inteligencia se identificaba con la curiosidad infantil que debía ser estimulada.

Por otra parte, la definición social del niño como un agente cultural autónomo, cuyas actividades espontáneas constituyen una condición para su desarrollo completo, se elabora en forma continua. Por medio de inventos y desarrollos pedagógicos, por la acción de los distintos "agentes" de la educación, incluidos padres de familia, maestros, inspectores y educadores, y por la acción de escritores, artistas, sicólogos y sicopedagógos. Este sistema educacional, que incluye las relaciones entre los agentes de la educación, los niños, las familias, y los productores de bienes y servicios para los niños, conlleva la progresiva constitución de un "mercado" para la primera niñez. Diversos objetos, tales como juguetes, libros de cuentos y poesías infantiles, y la asesoría sicológica y pedagógica, se presentan como medios para mejorar la transmisión cultural de la familia durante este período. La existencia de este sistema permite hablar de una definición social de la primera niñez: las innovaciones e inventos se ven concretados en instituciones, en productos simbólicos y materiales, en conjuntos de relaciones objetivas. Todo el sistema se mantiene por los distintos intereses de los grupos que tienen que ver con el proceso; este mismo proceso significa una racionalización que a su vez conduce a la institucionalización de la primera niñez.

En la presente investigación nos interesaba conocer cómo esta definición social de la niñez ha ido penetrando poco a poco en los centros dedicados a la educación pre-escolar. En las páginas que siguen se presentan algunos resultados obtenidos mediante entrevistas con los jardineros en dos Hogares Infantiles de áreas marginales urbanas de Bogotá, diferenciados entre si por el tipo de población que atienden. Son ellos el Hogar de "La Picota", ubicado en el barrio Palermo Sur, y el de "Rin-Rin Renacuajo", que se halla en la comunidad de los Chircales, ubicada en la zona sur chircalera, y que se encuentra fuera del perímetro urbano de la ciudad.

\section{La comunidad de los Chircales}

La comunidad de los Chircales, forma parte de una amplia zona de chircales, la más amplia de la ciudad según censo efectuado en 1975 por CENAC (CENAC, CAMACOL, COLCIENCIAS, 1976), que se extiende desde el barrio Tunjuelito hasta los límites con el municipio de Usme. El Hogar Infantil "Rin-Rin Renacuajo" se halla en el extremo norte del terreno sobre las lomas o cerros de Guacamaya, en lo que viene a ser la parte alta del barrio El Consuelo, barrio que anteriormente también fue un terreno chircalero. La zona chircalera del sur incluye las dos terceras partes de todas las unidades de producción artesanal de ladrillo de la capital. Se contaron, en 1975, 263 chircales artesanales, de los cuales, una alta proporción, el 83 por ciento, pertenece a la familia Pardo Morales, dueña de las antiguas haciendas El Consuelo, Marco Fidel Suárez y Los Molinos.

Desde mediados de los años 70 , el número de chircales ha venido disminuyendo constantemente, debido principalmente a las ventas de tierras de la zona. Por ejemplo, el ICT construyó la urbanización "Ciudad Bochica" en esos terrenos, con más de mil viviendas que se han ido entregando desde 1980; en 1983 se comenzó la construcción de una de las urbanizaciones de vivienda sin cuota inicial, "Marruecos", por la firma Inversiones Bogotá, en terrenos anteriormente explotados como chircales.

Puede decirse que la población de la zona debe estar entre 3 mil y 6 mil personas, teniendo en cuenta que las familias chircaleras son numerosas, posiblemente con más de 
8 miembros, ya que en esta comunidad chircalera se sigue viendo al niño como una adición a la fuerza de trabajo familiar. Se observa que hay un predominio notable de niños menores de 10 años; la directora del Hogar Infantil dice que debe haber por lo menos 3 mil niños en edad pre-escolar en toda la zona chircalera del sur, pero sólo se atienden 80 niños que es el cupo asignado por el ICBF para ese hogar. Muchos niños entre 3 y 10 años trabajan en los chircales.

La mayor parte del terreno en donde se ubica el Hogar Infantil "Rin-Rin" continúa perteneciendo a la familia dueña de la antigua hacienda de "Los Molinos". Pero también hay algunos chircaleros propietarios. Parece que toda la zona —que hemos llamado la comunidad de los chircales - esta fuera del perímetro urbano, según informaciones del principal dueño de los terrenos. Geográficamente, la comunidad limita con los barrios vecinos que son El Consuelo, El Socorro, Marco Fidel Suárez, Las Lomas y Molinos del Sur. Es una ventaja para los propietarios el no estar incluidos dentro del perímetro urbano, en especial por el aspecto de impuestos, catastro y valorizaciones. Pero significa una gran desventaja para los habitan-Les de la zona, ya que no tienen servicios públicos como veremos más adelante.

Los habitantes de esta comunidad están constituidos por familias dispersas que no cuentan con ningún grado de organización como otros barrios capitalinos; por ejemplo, no existe la Acción Comunal que podría asumir responsabilidades y tareas colectivas relacionadas con el bienestar de la población.

La Fundación encargada de la administración del Hogar Infantil es la entidad que asume esta responsabilidad; los miembros de la Fundación no ven ningún problema en que ello sea así, y más bien señalan que la apatía de la gente y su incapacidad para organizarse, son las causas de esa falta de organización comunal. La Fundación es vista por sus miembros (apenas 4 personas de fuera de la comunidad, pero incluyendo a la directora del Hogar Infantil y al dueño del terreno) como si ella fuera "toda la comunidad" y como si no hubiera necesidad de ninguna organización de la población. Todo ello explica, por lo menos en parte, la ausencia total de instalaciones comunitarias, como salones comunales, escuela, canchas de deporte y otras. Se nos informó que la Fundación tiene lotes para ampliar el Hogar Infantil y para construir una escuela y un centro de salud, pero hasta la fecha esos terrenos no han sido utilizados por la comunidad en ninguna forma. Tampoco hay capilla o iglesia; la población acude a la Parroquia de Tunjuelito.

Se trata de terrenos áridos, como todos los que se dedican a la producción de ladrillo en forma artesanal, por lo cual no hay árboles. En las temporadas de invierno, la tierra se convierte en una superficie lisa, con una humedad penetrante. y como es un terreno montañoso, la temperatura es baja y se hace difícil el acceso a los ranchos por el barro que abunda por todas partes. Durante la época de lluvias, es necesario colocar piedras y tablas para poder salir de las casas. Igualmente, en las temporadas secas, hay mucho polvo; hombres, mujeres y niños trabajan al sol durante largas jornadas.

\section{Salud}

Según informes de las jardineras de "Rin Rin Renacuajo", no ha habido acciones por parte de instituciones oficiales para cambiar estas condiciones; tampoco programas de saneamiento ambiental que hacen inmensa falta en la zona. El humo de los hornos en donde se cuece el ladrillo también afecta la salud de los chircaleros y se presentan casos de silicosis, que unida a la desnutrición, agrava las posibilidades de que se presente la tuberculosis. 
La mayoría de los trabajadores son trabajadores independientes, por lo cual no se encuentran afiliados al ISS. En casos de enfermedad acuden a los centros de salud de los barrios aledaños, principalmente a Tunjuelito; nunca ha habido programas de medicina preventiva en la comunidad, según informaciones de las jardineras. Los conocimientos de la población chircalera sobre la salud son por lo general escasos; como en las demás poblaciones marginales de la ciudad, los servicios en los centros de salud son, por lo general, pésimos. Allí se carece de los recursos elementales, tanto humanos como materiales. El centro de salud no siempre cumple funciones de medicina preventiva o de saneamiento ambiental que tanta falta hacen; tampoco existen servicios educativos en salud. No se han organizado comités de salud a nivel de la comunidad y por lo mismo, para todo se acude a la droguería, y en casos graves se busca la ayuda del representante del ICBF.

Las condiciones de vida, el tipo de trabajo, la falta de servicios públicos, todos contribuyen a que la salud de los chircaleros sea muy deficiente. Aunque no existen estudios sobre la morbilidad de la comunidad, en las zonas chircaleras vecinas se han encontrado altos índices de epidemias como gastroenteritis, diarreas en los niños, gripes frecuentes, enfermedades en las vías respiratorias, es decir, enfermedades diversas que podrían evitarse ya que son causadas por factores como la desnutrición, la falta de qua potable y otros factores ya enumerados.

\section{Infraestructura y servicios públicos}

Para llegar a la comunidad, los dueños del terreno han abierto una especie de camino para subir a los cerros, por donde transitan en forma exclusiva los camiones que transportan el carbón para los hornos y el ladrillo. No existe, por tanto, un sistema de transporte público dentro de la zona. Los habitantes deben bajar hasta la avenida 13 (o carretera a Usme) para utilizar el transporte hacia el sur o norte de la ciudad. La mayor parte de los recorridos que deben hacer, los hacen a pie. Existe en la zona una red de sendas o caminos para peatones, burdamente construidos por los mismos habitantes. La falta de carretera dificulta el transporte del ladrillo; las mujeres y los niños cargan bultos y bolsos pesados con los artículos para su subsistencia.

Aunque una gran parte de la población ha residido en la comunidad desde hace cerca de 30 años, y de hecho la zona se halla dentro del perímetro urbano, en 1984 todavía no existen en ella los servicios públicos. La luz es de contrabando y el agua llega a la comunidad por medio de piletas públicas que no siempre funcionan adecuadamente. El Hogar Infantil tiene servicio de agua como algo excepcional dentro del barrio. Las mujeres usan los pozos de agua llovida que se recoge para fabricar la arcilla. El agua en las piletas llega contaminada, por daños en las mangueras; los cortes de agua son muy frecuentes en esta zona.

La falta de alcantarillado hace que las condiciones ambientales sean pésimas. Algunas familias han instalado letrinas que por lo general se hallan en estado lamentable. Esto produce malos olores y hay varios focos de infección por los insectos, zancudos, moscas, etc. A estos focos contribuyen los animales domésticos y el hecho de que la gente utiliza el campo abierto para defecar. No existe ningún servicio de recolección de basuras; por lo que se trata de predios rurales. 


\section{La vivienda}

En general, en la zona chircalera, la vivienda es muy pobre. Consiste en un rancho de ladrillo o adobe, conformado de una sola pieza, con la cocina instalada dentro de la misma pieza. Las familias utilizan el cocinol o la leña para cocinar. Como las viviendas carecen de agua, las mujeres lavan cerca del pozo de agua lluvia, a veces van a las pilas comunales. Como los cortes de agua son frecuentes, las mujeres y los niños hacen largos recorridos para conseguir el agua y la cargan en baldes, ollas y toda clase de utensilios. Sólo las familias con mayores recursos económicos han puesto agua en las casas y tienen lavadero en el patio.

La gente no suele hacer mejoras en los ranchos, debido a que éstos no le pertenecen y por lo que constantemente temen perder su vivienda, al perder el empleo o al cambiar de trabajo.

En las piezas normalmente hay una o dos camas. El número de personas por pieza varía. Las familias son numerosas, con un promedio de 6 niños por familia. Los niños apenas se llevan un año de diferencia dentro de cada familia.

Casi nunca hay mesas en los ranchos; para comer, los chircaleros se sientan en el suelo o en la cama, aunque hay unas butacas para sentarse, cajones para la ropa, y otros utensilios. En muchas casas hay grabadora, radio, televisor y hasta equipos de sonido por los que se pagan cuotas bastante altas, y que constituyen objetos de consumo lujosos, que además conllevan prestigio social. Adornan las paredes diversas imágenes del Sagrado Corazón, la Virgen María, a veces fotografías de las familias, fotos en color del matrimonio, etc. Hay toda clase de baratijas, y utensilios de cocina que se colocan en el suelo o se cuelgan en las paredes como en las casas campesinas. Según el estado económico de las familias, puede haber un armario, o una biblioteca, fuera del televisor. En los ranchos, es muy frecuente encontrar animales domésticos. El burro o la mula para mover el molino, y perros, gatos, gallinas, dentro y fuera de la casa. También se crían cerdos, ovejas, revelando la persistencia de costumbres campesinas. La mujeres conservan la costumbre de hilar lana pero rara vez saben tejerla.

En toda el área chircalera, la mujer asume trabajos que exigen gran fuerza física en la producción de ladrillos, y además procura aumentar sus escasos ingresos haciendo dulces o empanadas, o cosiendo. Al respecto es interesante anotar que en una recopilación histórica sobre el trabajo de la mujer, encontramos un texto de Hedwig Dohm, escrito en 1874, sobre la división del trabajo que puede aplicarse a la situación de los chircales. Dice así.

"Las condiciones económicas y las ideologías sobre la mujer se parecen bastante en toda Europa civilizada. En los escritos sobre el trabajo de la mujer, no cabe duda; en ninguna parte ni en ninguna etapa se ha impedido a la mujer el hacer las tareas más penosas y más desagradables... Para las clases bajas parece valer el principio: entre más duro y más agotador el trabajo, mejor para la mujer. (Subrayado en el original).

\section{Nivel educativo}

La mayoría de los habitantes de la comunidad chircalera no han cursado sino uno o dos años de primaria, y muy frecuentemente es el haber repetido varias veces el primer año. Se observa una relación clara entre el status económico y el nivel educativo dentro de la 
comunidad chircalera. Las personas que han adquirido mejor nivel económico, por ejemplo, quienes son propietarias de un chircal o de un camión, por lo general también han cursado más años de educación formal, básicamente la primaria. La generación más joven, los hijos de los actuales chircaleros, estudian en una proporción no muy grande en colegios privados, muchos de ellos de carácter religioso y de bajo costo, y no trabajan en la producción de ladrillo. A veces trabajan como ayudantes de los camiones, o de otras faenas familiares; las hijas colaboran en todas las labores domésticas. Los jóvenes en general no trabajan todo el día, ni tampoco necesariamente para complementar los ingresos familiares. Muchos niños menores de 10 años administran con frecuencia su propio dinero para sus necesidades de vestuario fundamentalmente.

La mayoría de los chircaleros vivió su infancia en el campo, en los pueblos de Boyacá, en especial de Jericó, de donde muchos provienen. En el campo, los varones fueron a la escuela del pueblo, las hijas mayores por lo general tuvieron que quedarse en la vereda; sus padres les impidieron ir a la escuela porque no lo consideraban conveniente ni necesario. Entre las mujeres el grado de analfabetismo es bastante más alto que entre los hombres. Así se tiene una razón más para subordinar a las mujeres, ejercer el dominio sobre ellas, ponerles obstáculos para salir de la comunidad, e impedirles el buscar cambios en su vida cotidiana, en su trabajo o en su capacitación.

En la generación actual parecen igualarse las diferencias entre los sexos, en cuanto a la educación. Probablemente esto se debe a las influencias urbanas y a ciertos inicios de una movilidad ocupacional que impone la necesidad que se les presenta a hombres y mujeres, de buscar algún ingreso fuera de la comunidad. Los padres no parecen obstaculizar el ingreso de niños y niñas a la escuela. Sin tener información cuantitativa al respecto, se observó que una gran parte de la población chircalera tiene conciencia de la necesidad de la educación para los jóvenes. Aunque continúa una explotación laboral masiva de la población infantil y juvenil, existe también un concepto claro sobre la necesidad de obtener los conocimientos propios de la escuela.

\section{La situación escolar}

En los barrios chircaleros, muchas veces fue la población misma la que construyó o financió el edificio para la escuela. Los maestros son enviados por la Secretaría de Educación del Distrito Especial. Como en todo el sector sur de Bogotá, la escuela carece de recursos materiales y humanos en forma aguda. Además, por pertenecer al sector más "marginado" de la ciudad, los profesores no quieren trabajar allá. Existe un rechazo comprensible, debido a las condiciones deficientes para la enseñanza: los edificios se encuentran en malas condiciones sanitarias, los profesores deben enseñar en grupos que incluyen simultáneamente varios niveles y edades de niños. Subsisten todas las características de la escuela tradicional rural. Esas condiciones imposibilitan una enseñanza efectiva. Los alumnos de padres con recursos económicos más altos van a colegios privados (primaria y secundaria).

Los maestros deben enseñar a grupos muy heterogéneos. Las condiciones escolares causan una deserción escolar alta. Muchos alumnos, entre los 10 y los 12 años, tardíamente ingresan al primer curso de primaria. Después de haber iniciado varias veces el mismo curso, muchos no vuelven nunca a la escuela.

Algunas de las desventajas que presenta el niño chircalero que afectan su rendimiento escolar son: 
- la desnutrición propia y la de su madre durante el embarazo,

- el trabajo infantil,

- y las condiciones complejas de la vida de los chircaleros, en donde el niño recibe pocos estímulos para su desarrollo síquico y mental, lo cual hacer ver la enorme importancia de la educación preescolar para ellos.

\section{La producción de ladrillo}

El estudio que hemos citado anteriormente ${ }^{83}$ menciona que la zona chircalera del sur de la ciudad, en la cual se ubica el Hogar Infantil "Rin Rin Renacuajo", como lo hemos explicado, es aquella en donde se dan relaciones de producción más atrasadas en la industria de producción de ladrillo.

Los chircales artesanales se destacan por la producción de ladrillo cocido y recocido, con muy baja tecnología, poca inversión de capital y el uso intensivo de la fuerza de trabajo, en la cual se subraya la fuerte participación de mujeres y niños. La baja composición orgánica del capital, el bajo nivel tecnológico, la fuerte competencia de la producción artesanal frente a la moderna, la presión de los precios, la mala calidad de la producción artesanal, sus riesgos e inestabilidad, y la apropiación que hace el terrateniente de parte del plusvalor generado, son factores que confluyen para hacer muy precaria la situación de los chircaleros. Más de un observador se sorprende al constatar que subsiste la producción artesanal de ladrillo, y ello sólo puede explicarse en términos de la integración que se logra en el modo de producción capitalista de formas atrasadas de producción que representan un aporte significativo a la acumulación de capital.

El estudio de la Universidad INCCA que ya hemos citado, señala claramente que tanto el arrendatario como el obrero asalariado en este tipo de producción artesanal resultan sobre-explotados. Dicho estudio concluye diciendo que se presentan dos problemas principalmente en los chircales, en primer lugar, una baja tecnología originada por la baja composición orgánica del capital y la falta de financiación, y en segundo lugar, una precaria situación de vida de la población chircalera, generada por la forma de propiedad sobre los medios de producción, especialmente por la forma de tenencia de la tierra. Se señala por último que estos factores producirán un desaparecimiento de los centros de producción artesanal, o por lo menos un estancamiento, pues las empresas altamente tecnificadas cubrirán la demanda del producto. El dueño mayoritario de los chircales le calcula unos 15 años a este proceso de eliminación de la producción artesanal.

El estudio de CENAC refuerza estas conclusiones y reitera que la fuerza de trabajo se paga en forma muy exigua, por debajo de su valor. Según los comentarios recogidos localmente en este estudio de los Hogares Infantiles, se trata de una producción rentable para los dueños de los chircales, precisamente por la sobre-explotación de la fuerza de trabajo familiar. La mayoría de los chircaleros, como queda dicho atrás, son trabajadores "libres" en el sentido de que no tienen la propiedad de los medios de producción.

Se trata de que la plusvalía generada por los productores directos de ladrillo se realiza a través del mecanismo del intercambio desigual, que lo transfiere al sector moderno, como lo señalan Zamudio y Clavijo ${ }^{84}$ :

\footnotetext{
${ }^{83}$ CENAC, Camacol, Colciencias, DAPD. Diagnóstico del estado económico y tecnológico de la industria ladrillera en el país. Bogotá, 1976.

${ }^{84}$ Zamudio, I y H. Clavijo. ¿El barrio popular: marginados o ejército industrial de reserva? Controversia, CINEP. Bogotá, 1983.
} 
"El más primitivo de los chircaleros se vincula al capital y lo hace a favor de éste, pues los altos costos y el bajo volumen de la producción lo obligan con frecuencia a vender a precios inferiores al valor y a aceptar modalidades de pago favorables al constructor. De paso, esto obliga al pequeño productor a sobre-explotar el trabajo de sus familiares o empleados, y a sufrir una escasez crónica de capital que le resta toda posibilidad de desarrollar sus medios de producción".

Es decir, el chircalero no tiene posibilidades de ahorro de ninguna clase. El abaratamiento de costos en la producción artesanal hace que una buena parte de esta producción se destine a la autoconstrucción de viviendas en los barrios populares ${ }^{85}$.

Por el corte de mil ladrillos, se pagaban en 1983, \$300. Según la capacidad, entrenamiento y habilidad de la mujer para este oficio, se necesitan ocho o más horas para producir ese millar de ladrillos. Los niños principalmente se emplean para cargar los ladrillos; los menores, entre 3 y 5 años cargan hasta 3 ladrillos, los mayores cargan muchos más. El trabajo en los chircales es duro como puede verse en el rostro envejecido prematuramente de tantas mujeres y hombres chircaleros; las condiciones ambientales, el trabajo a pleno sol, la falta de salubridad en esta población, todo ello hace posible comparar sus condiciones con las de los sectores más atrasados del campesinado. (Recuérdese la película "Chircales" de Jorge Silva y Martha Rodríguez).

Todos los miembros de la familia trabajan en el proceso de la producción de ladrillos, sin distinción de edades ni de sexo. El trabajo infantil se da en varias etapas del proceso; por ejemplo, los niños cargan carretillas pesadas con el ladrillo no cocido para colocarlo en el horno; ayudan también a pasar los ladrillos hasta la puerta del horno, en donde el hombre los coloca, aunque la mujer algunas veces también ayuda en esta tarea. Los niños cargan también el carbón para el horno que han dejado los camioneros al filo de la carretera destapada que sube por los cerros; rara vez ayudan a cortar el ladrillo; por todo ello, niños y adultos en los chircales permanecen entre el barro, cubiertos de lodo sus pies, brazos, manos y piernas a toda hora. Los molinos de los pozos de agua llovida son manejados por burros, caballos o mulas, y allí es donde se prepara el barro. Los hombres son quienes extraen la tierra de las lomas carcomidas, aunque a veces la mujer también presta su fuerza de trabajo para lo mismo, siendo ésta quizá la tarea más exigente de todas, mediante las pesadas picas y palas. A veces no hay lomas directamente detrás de los chircales, por lo cual los chircaleros deben trasladarse a lugares distantes del chircal para conseguir la materia prima.

Cuando se visita este terreno en días de sol, y hay plena producción, se pueden ver grandes cantidades de ladrillos al sol, secándose, otros montados en pilas para llevarlos al horno, en donde se colocan en hileras, intermediando una hilera de carbón, hasta una altura aproximada de 354 metros. Luego se cubre enteramente con carbón, dejando un hueco para regularizar la temperatura, que tiene la forma de chimenea ${ }^{86}$.

\section{La definición social de la niñez entre los jardineros del Hogar Infantil Rin-Rin Renacuajo}

Este es uno de los pocos Hogares Infantiles del ICIBF que incluye a un hombre entre los jardineros, lo cual sorprende por prevalecer en la comunidad de los chircales patrones de conducta y valores de tipo muy tradicional. La concepción que tienen los jardineros de

\footnotetext{
${ }^{85}$ Ibid.: $38-39$.

${ }^{86}$ Cf. Velásquez, F. y P. Vila. El Proceso productivo en los chircales de Bogotá. DAPD. Bogotá, 1974. 
los niños de los chircales se ha desarrollado, como veremos, contrarrestando las concepciones que tienen de éstos sus padres, por lo general trabajadores chircaleros.

\section{Autonomía, espontaneidad, creatividad}

Varios de los jardineros se expresan sobre el niño enfatizando su autonomía, su capacidad creativa, su imaginación y sus posibilidades para ampliar sus relaciones y "salir" del mundo de los chircales. Una jardinera, estudiante de educación pre-escolar en la Universidad INCCA nos da una idea de lo que debe ser un niño ${ }^{87}$.

Un niño que esté bien, en mi concepto, debe ser un niño que esté en buena salud física, sicológica, mental. El fin del Hogar Infantil debe ser el de dar al niño la oportunidad para que se exprese, para que pueda ser espontáneo, que desarrolle su creatividad y su autonomía, así como su imaginación.

Me parece que es indispensable que el niño aprenda a ser autónomo, que no esté dependiendo de nadie, es decir, que no dependa en forma absoluta de ninguna persona, ya que el niño tendrá que depender de todos modos de algún adulto mientras crece. Pero es que hay niños que no se atreven a dar ni un paso sin que se les esté diciendo qué hacer. Eso no me parece bien. El niño debe ser espontáneo, debe coger los juguetes que quiera, jugar, moverse libremente.

Yo diría que todas las actividades del Hogar Infantil se dirigen principalmente a que el niño sea autónomo.

Esta jardinera constata además que la formación de la persona se da a través de toda su vida. Ocurre una acumulación de experiencias que van formando al niño poco a poco; se debe tener un trato especial con los niños, pues a ellos cualquier "cosita les afecta". Estos jardineros tienen también una concepción distinta en el sentido de que ven las posibilidades de aprendizaje que ellos, como jardineros, tienen en el proceso. "Uno aprende mucho de los niños"; "los niños mismos a veces nos dicen cómo organizarles una actividad". Es decir, este grupo no mantiene con rigidez el papel del educador frente al educando, sino que goza cuando el niño se convierte en educador, como lo expresaron varios de ellos, al referirse a los paseos que hacen por las lomas escarpadas de los chircales que los niños conocen como la palma de sus manos. Los jardineros ven también la importancia de ayudarle al niño a liberarse de los sentimientos que tienen respecto a su sumisión e "inferioridad" frente a los niños de barrios o sectores más avanzados. Todo el proceso educativo debe conducir hacia ese proceso de liberación.

\section{La discriminación social}

Puede afirmarse que toda la comunidad chircalera sufre de algún modo procesos de discriminación económica, social y cultural. Los niños, por lo tanto, no escapan a la discriminación que se les presenta en diversas formas. Los jardineros son conscientes de estas actitudes discriminatorias, lo cual a veces los lleva a asumir un papel un poco paternalista, en el sentido de querer proteger a los niños de esas actitudes.

Mucha gente nos dice que esos niños chircaleros son tonticos, brutos, que no saben nada; se piensa que en este sector las personas no tienen inteligencia, que no saben

\footnotetext{
${ }^{87}$ Las citas entre comillas y los apartes que se destacan en el centro de página son tomados de las entrevistas llevadas a cabo con los jardineros, a menos que se cite una fuente distinta. Los nombres utilizados para personas son ficticios. 
pensar. Pero fíjese que los niños de los chircales son capaces de enseñarle a uno distintas cosas.

Y una jardinera que pertenece a una familia chircalera nos dice:

Siempre, en donde existen chircales, en los alrededores hay discriminación. El barrio allá, el chircal acá.

Destacamos cómo esa discriminación de los barrios vecinos hacia los chircales, se da entre personas que pertenecen a los sectores populares; casi todas ellas perciben ingresos muy exiguos y su capacidad de ahorro es casi inexistente. Dice una jardinera.

Pero también la gente del sur coloca a los chircaleros en posición inferior, sólo porque ellos tal vez tienen una casa o alguna comodidad mayor.

Estas actitudes que señalan a los chircaleros como personas de inferior condición, se observa sobre todo en la escuela de los barrios vecinos, en donde los niños de los chircales son despreciados y rechazados por otros niños. Naturalmente que estas conductas infantiles son transmitidas a los niños por sus padres o por los mismos maestros de escuela. En el trabajo de campo realizado para este estudio, pudimos observar que los mismos niños chircaleros confunden la limpieza con la tez blanca, el vestido bonito, el peinado arreglado, y que para ellos estos atributos de la limpieza son equivalentes a la inteligencia. Esta clase de prejuicio se aplica más o menos explícitamente, a todos los sectores pobres, y parece ignorar las condiciones básicas que se requieren para estar siempre limpio y arreglado, como son el tener acueducto, alcantarillado e ingresos suficientes. Dice una jardinera.

Lo que pasa en la escuela es que se desconocen las condiciones en que viven las familias chircaleras. Entonces devuelven a los niños porque llegan embarrados, 0 porque tienen piojos. ¿Pero cómo acabar con los piojos cuando no hay servicios, no hay agua, no hay alcantarillado? Los niños de los chircales siempre han vivido en mucha sumisión porque no se conoce su realidad.

\section{Agresividad}

Uno de los problemas que a diario confrontan los jardineros tiene que ver con la agresividad que expresan los niños. Una de las jardineras explica que:

Desde pequeñitos estos niños se crían en un ambiente hosco, y es por esto que son bastante agresivos, sobre todo los mayores, porque han vivido en ambientes muy reacios...

Y es que todo eso viene desde los antepasados de la gente, en primer lugar porque no han tenido educación, ni tampoco han tenido oportunidad de ir a otra parte en donde reciban otra clase de trato. Y podemos decir que son las condiciones de vida, porque les toca estar trabajando de una forma tan dura, y la situación económica influye mucho.

Es posible que la agresividad provenga de que los niños a veces se sienten encerrados en el Hogar Infantil, puesto que, en cierto modo, a pesar de vivir dentro de la ciudad, ellos disfrutan de una vida más parecida a la del campo; tienen espacio para correr libremente, no hay tráfico que les impida andar por los chircales, las viviendas aún se encuentran 
dispersas las unas de las otras. Algunos jardineros comentan que al llegar los niños por primera vez al Hogar se sienten un poco encerrados por estas diferencias. La directora del Hogar incluso llega a decir que los niños al principio se sienten "encarcelados".

Naturalmente que la agresividad puede tener otras causas, como las relacionadas con el problema de una educación o crianza que tienen características represivas, como se deduce de las observaciones que hicieron los jardineros, por ejemplo sobre el tema de la sexualidad de los niños.

\section{La sexualidad infantil}

En este Hogar Infantil, contrariamente a lo que ocurre en el de "La Picota" en Palermo Sur, como veremos más adelante, los jardineros no tuvieron problemas en hablar con franqueza de los problemas de tipo sexual que ellos observan en los niños. Cuentan por ejemplo que muchas veces ha ocurrido que un niño desviste a una niña, o que un niño se acuesta encima de una niña, y episodios semejantes. Los jardineros opinan en general que la conducta de los niños en estos aspectos es de carácter imitativo, es decir, que los niños con estos "juegos" están imitando el acto sexual que ellos muy posiblemente han observado en sus casas. Debido a que los ranchos de los chircales por lo general no tienen sino un cuarto y una o dos camas, los niños duermen con sus padres o con otros adultos con quienes comparten la vivienda. Los niños más pequeños duermen en la cama de sus padres, o duermen con niños más grandes, por lo cual debe ser frecuente no sólo el observar las relaciones sexuales de los adultos, sino también ser objeto de aquellas.

Entre los jardineros, hay distintas maneras de observar y de tratar esta clase de problemas, ya que ello depende de la madurez de cada uno, de la edad, de sus propias experiencias, relaciones y socialización. Pero no hay duda de que en este grupo de jardineros hay una percepción de la sexualidad infantil y de sus manifestaciones mucho más avanzada que la de las jardineras de "La Picota", en donde el tema del sexo simplemente no se trata, se reprime, como cosa que no atañe al Hogar Infantil.

En los chircales, los niños perciben visualmente lo que es el sexo, o las relaciones sexuales de los adultos, pero al ir descubriendo lo relativo a su propio cuerpo y a la sexualidad, no lo expresan verbalmente, sino con juegos sexuales de carácter imitativo. Este comportamiento puede interpretarse como un indicador de formas de represión sexual que se incluyen en la socialización de estos niños dentro de su familia respectiva; no significa que haya, por parte de los jardineros, una supresión del tema de la sexualidad. Ellos indican que los niños rara vez hablan sobre el sexo, no preguntan pues para ellos es un tema prohibido, un tema que es tabú entre sus padres. En este medio familiar se suprime el tema de la sexualidad; el sexo y lo relacionado con él se refiere a "lo sucio", "el pecado", y con el silencio que imponen las familias al respecto, el niño aprende que "de eso" no se habla.

Casi todo lo que el niño aprende sobre su cuerpo conlleva las mismas actitudes negativas. La desnudez es vista como algo prohibido por estas familias; inclusive con los niños recién nacidos, entre ellas se acostumbra tapar el pene, porque es "lo feo", "lo privado". Con las niñas pequeñas ocurre lo mismo, siempre se les está diciendo que se tapen. Estos ejemplos indican cómo la socialización de estos niños se hace de manera represiva; los adultos no tienen conciencia de que la educación sexual forma parte de esa socialización, de que la sexualidad se manifiesta en el niño desde que nace, de lo importante que es para el niño no tener una visión parcelada del hombre que acepte como 
natural la represión sexual, la separación de los sexos, y la dominación de unos sobre otros.

Es evidente que los jardineros tienen una gran responsabilidad en el manejo de los problemas sexuales que se presentan con los niños ---realmente se trata de problemas por las experiencias traumáticas y violentas que con mucha frecuencia viven los niños. ¿Cómo superar estos problemas si se suprime el tema de la sexualidad? Los jardineros tienen conciencia de estas dificultades y afirman que la agresividad de los niños puede también ser explicada por estas formas de socialización. Es sorprendente que en un contexto bastante reacio a los cambios, como es el de la comunidad de los chircales, y frente a la complejidad del tema y la dificultad para tratarlo, los jardineros contrarrestan esta actitud represiva frente a la sexualidad infantil y tratan el tema con naturalidad y libremente, con franqueza, y sabiendo además que es difícil encontrar la última palabra acerca de cómo manejar estas situaciones. El jardinero nos dice:

Los niños preguntan muy pocas cosas sobre lo sexual, pero ellos presencian las relaciones sexuales de sus padres. Tuvimos un caso hace poco de un niño que se acostó sobre una niña aquí en el jardín, imitando los movimientos de sus padres en el acto sexual, y la niña estaba quieta; en ese momento pasó por el Hogar el papá de la niña, se puso muy bravo y me dijo que había que castigar al niño - Los padres de éste me llamaron para decirme que el niño estaba haciendo groserías. Pero ese niño vive en un rancho de una sola pieza, y él no comprende por qué se le castiga al hacer lo que su papá hace.

También hemos tenido casos de niños y niñas con cierta precocidad sexual, y no es fácil saber qué hacer, frente a determinadas conductas de los niños, por ejemplo, cuando se masturban o se tocan el uno al otro. Yo resolví que lo mejor era desnudarlos a todos --son niños de 5 a 6 años--y explicarles que los niños tienen pene y las niñas vagina; les dibujé las figuras en el tablero, y les dije que se miraran todos para ver que así era, y todo eso lo hice con naturalidad y creo que los niños quedaron tranquilos.

Pero el problema es con los padres que nunca hablan de lo sexual, y si mencionan las relaciones sexuales lo hacen refiriéndose a ellas como algo sucio, grosero, vulgar, cuando al niño hay que mostrarle que lo relacionado con el sexo es una función natural que el niño va a llevar a cabo cuando sea adulto.

Los niños se bañan al tiempo con las niñas y creo que eso ha ayudado a que tomen lo de la sexualidad con mayor naturalidad.

En general, tanto para este jardinero como para las demás jardineras de "Rin-Rin", hay claridad sobre la presencia de la actividad sexual infantil en cada niño; ellos saben que los niños responden a estímulos sexuales desde las primeras semanas de su nacimiento; comprenden el papel importante de los adultos respecto a la comprensión que el niño tenga de su propia sexualidad, y anotan que en esta comunidad la ausencia de la figura paterna es muchas veces un problema que se añade a las dificultades de los niños en este sentido. El jardinero sin duda contribuye a que los niños remplacen la figura del padre ausente con la suya. 


\section{Aprender a compartir}

En contraste con lo que ocurre en otros Hogares Infantiles, en el de Rin-Rin Renacuajo se otorga claramente una función social a la educación pre-escolar. Es decir, ésta no sólo se concibe como un aprestamiento para el ingreso a la escuela, sino como un medio para que el niño aprenda a comportarse como un ser social. Dice uno de los jardineros:

Es que para el niño, el Hogar Infantil significa sobre todo que él sale de su egoísmo, aprende a compartir. Mi hijo, que está en el Hogar, tenía el problema de que no quería compartir con nadie sus cosas. Aquí cambió ese modo de ser completamente. Ahora comparte todo con los demás niños, así he visto que ocurre con éstos, ellos aprenden en el Hogar a compartirlo todo.

En más de sesenta entrevistas que llevamos a cabo para este estudio, resulta extraño que sólo una vez se nos hablara de la importancia del comportamiento del niño relacionado con los demás; el respeto por el otro, el apropiarse de los valores necesarios para la vida social, para un respeto mutuo, para la igualdad en las relaciones sociales, que nos fueron explícitamente tratados en los otros Hogares Infantiles incluidos en el estudio. Es sorprendente que los jardineros no mencionaran este papel del Hogar Infantil respecto a la socialización de los niños con más frecuencia, siendo que todos ellos observan niños más egoístas que otros, o niños con conductas sociales más avanzadas.

\section{La alegría}

La impresión general que se tiene al entrar a "Rin-Rin" es que los niños gozan, están alegres, libres de correr y moverse de un lado para otro. Las observaciones que se hicieron del proceso pedagógico comprueban que existe un ambiente de libertad, informalidad, alegría general. El niño no sólo es reconocido por los demás -tanto por sus compañeros como por los adultos - sino que se siente reconocido. Así los niños reciben estímulos permanentemente a medida que se confirma su progreso en las distintas áreas de la educación pre-escolar. La jardinera de familia chircalera nos resume sus impresiones así:

Los niños cuando primero llegan al jardín, son tímidos, pero cuando se han adaptado se vuelven alegres y ellos mismos repiten que están contentos porque en el jardín tienen cosas con las cuales jugar. Los niños dicen: aquí nos dan comida, nos prestan juguetes, nos quieren, podemos jugar, en cambio en la casa no.

No es que los niños rechacen a sus padres, pero nos dicen: en la casa no tengo amigos, no tengo con quién jugar, mi mamá está trabajando y mi papá también. Y es cierto que muchas veces las mamás no tienen tiempo ni para cocinar por su trabajo en la producción del ladrillo; entonces los niños se amañan mucho acá. Tienen sus amiguitos y aprenden mucho y en todas las actividades están desarrollando alguna de sus capacidades.

Los padres poco se dedican en su casa a los niños; las mamás más que todo se dedican a preparar los alimentos, pero no se ponen a jugar con los niños, ni a charlar con ellos. No, eso no ocurre.

En otras palabras, los niños para las familias chircaleras son alguien a quien hay que alimentar, pero no alguien con quien se deba conversar o jugar; tampoco es visto como fuente de felicidad $\mathrm{o}$ alegría. Estas relaciones entre padres e hijos son diferentes 
evidentemente a las que se dan entre familias de sectores sociales distintos. También son distintas a las que se inculcan por parte de los educadores del Hogar Infantil: "el niño debe jugar, ser autónomo, creativo, experimentar". ¿Cuáles son las posibilidades de que estas concepciones liberadoras acerca de la educación pre-escolar lleguen a predominar y transformen los conceptos tradicionales de la cultura de estas familias? Dependerá en gran parte de la continuidad que el Hogar pueda establecer entre la educación impartida a los niños y aquellos procesos educativos que emprenda con la comunidad chircalera. Sólo cambiando estos conceptos se podrá llegar a que el niño de los chircales cambie la concepción que tiene de sí mismo, como un ser sumiso, inferior, que siempre debe estar a órdenes de alguien.

\section{Relaciones entre niños y jardineros}

Uno de los jardineros afirmó en las entrevistas que los niños asisten al Hogar Infantil "por lo que allí pueden jugar y encontrar amigos". Entre éstos están incluidos los jardineros, a quienes los niños tratan con gran informalidad. Por ejemplo, los llaman por su nombre, los tutean, y hasta les tienen apodos cariñosos. Este trato de nuevo contrasta con el tipo de relaciones que se exigen en "La Picota": allí existen actitudes formales, de distancia entre los niños y las jardineras, y éstas deben ser llamadas como "profesora" o "señorita"'.

En la comunidad de los chircales, por su carácter tradicional, predominan en general relaciones de tipo autoritario, casi señorial, con el uso de apelativos como el don, doña y sumercé, típico este último de las regiones campesinas boyacenses con una cierta connotación de subordinación. Por eso debe destacarse la actitud informal impuesta por los jardineros en sus relaciones con los niños. Estos muestran una conducta abierta hacia todo el personal del jardín; incluidas las empleadas del aseo y de la cocina que pertenecen a la misma comunidad. Los niños entran y salen de la oficina de la directora con gran informalidad y se dirigen a ella y a los adultos en general con naturalidad y confianza en sí mismos.

Pero hay que anotar que las relaciones de los niños con los adultos de los chircales, sus padres y otros, son muy distintas. Posiblemente por su ubicación social, sus tradiciones y su origen cultural y geográfico, las relaciones entre los niños y sus padres se inscriben dentro de las estructuras de dominación-subordinación propias de las comunidades campesinas de antaño y todavía vigentes en muchas áreas rurales. Los roles de cada cual están definidos dentro de una estructura familiar de tipo jerárquico y se atribuyen según edad y sexo. En cambio, en el Hogar Infantil, los niños tienen relaciones informales, de amistad, hasta con "don Alejandro", el representante legal del Hogar, a quien se acercan sin timidez y con naturalidad.

Cabe destacar que la conducta informal de los niños en el pre-escolar probablemente tiene consecuencias en lo relativo al rompimiento de la estructura de subordinación impuesta en los hogares chircaleros, en donde el niño debe estar sometido a los adultos, simplemente por el hecho de ser niño. En Rin-Rin, se valora la personalidad de cada niño, se establecen relaciones de igualdad, amistad, compañerismo. Todo ello contribuye a fortalecer en el niño una actitud de mayor confianza en sí mismo y a superar el sentimiento "natural" de su inferioridad por su posición social y económica.

Ayuda a este proceso la ubicación del Hogar Infantil dentro de la misma comunidad de los chircales. Los niños llegan sin dificultad porque conocen bien el terreno; se encuentran en su ambiente natural, pueden convertirse en educadores de los jardineros por su 
conocimiento de senderos y caminos, se desempeñan fácilmente en las tareas que les imponen sus familias en la producción de ladrillo y se enorgullecen de "enseñar" a sus maestros. El Hogar hace intentos para integrar las actividades pre-escolares con el contexto cotidiano en el cual se desenvuelve la vida de los niños. El área de la producción se integra en las experiencias de éstos y al niño no se le aleja del mundo de los adultos, estando dentro del Hogar Infantil.

Es necesario insistir en que las relaciones entre niños y jardineros son diferentes a las que tienen con sus padres. Las primeras son relaciones de afecto, comprensión, confianza, mientras en las familias se trata al niño con brusquedad, dureza, y en cierto modo como si fueran objetos de propiedad de las familias. Los niños deben estar siempre a órdenes de la mamá y ésta con frecuencia les ordena ir, venir, traer esto, llevar aquello. Estas órdenes se imparten con expresiones de disgusto, a veces con gritos, y casi siempre se considera que el niño ha hecho mal lo que se le ordenó hacer. Rara vez se reconoce el trabajo de los niños; se les regaña permanentemente; se les imponen muchas sanciones por fallas en su rendimiento escolar o por motivos baladíes, sin comprensión alguna por parte de las familias. Posiblemente la misma relación de subordinación en que se encuentra la mujer se refleja en su trato con los niños. Es muy positivo, entonces, el trato de los jardineros con los niños que compensa la dureza de las relaciones familiares con relaciones de afecto y comprensión.

Esto no quiere decir, sin embargo, que los jardineros pretendan educar al niño para que éste viva siempre dentro de la comunidad chircalera. Por el contrario, existe en ellos el propósito de capacitar a los niños para una vida que transcurra fuera de los chircales. En esto los jardineros aciertan, pues la producción artesanal de ladrillo que caracteriza a estos chircales solo se mantendrá por un tiempo — de 15 a 20 años- según calculan los dueños de las tierras, y la población que depende de este tipo de producción tendrá forzosamente que adaptarse a las exigencias y condiciones de la sociedad global.

Puede afirmarse que los padres de familia aprecian ante todo el carácter asistencialista del Hogar Infantil, antes que su función educativa, a pesar de los esfuerzos hechos por los educadores en cuanto a lograr un cambio en esta clase de concepción. Parece que los hechos mismos ayudan a convencer a los padres de la importancia de la educación preescolar:

Cuando los padres vieron los resultados del Hogar, comenzaron a enviar a los niños con más facilidad. Por ejemplo, cuando una mamá ve que su hijo tiene buena alimentación, empieza a actuar de otra manera, poco a poco van entendiendo que a los niños les conviene el Hogar, por ejemplo, porque aquí se bañan, y así los niños pueden estar limpios. Pero hay padres que todavía desconfían del Hogar Infantil y piensan que es humillante el no ser ellos mismos quienes proporcionan alimentos a sus niños.

Existe una gran diferencia entre los niños que asisten al Hogar y los que no. Dicen los jardineros:

A un niño en la casa lo dejan abandonado, o que trabaje pero sin ningún estímulo. Lo dejan ahí al lado de la mamá o de otro niño más grande, y no les importa lo que le pase. A medida que los niños cambian en el Hogar, exigen de sus familias algunos cambios, por ejemplo, que tengan jabón y papel higiénico. Las familias empiezan a preocuparse, a arreglar mejor al niño, a bañarlo. 
El énfasis en la limpieza, entre los jardineros, parece corresponder al deseo de éstos de que los niños se identifiquen con niños de sectores más altos y así evitar el que sean objeto de la discriminación de la gente de fuera de la comunidad chircalera.

\section{Conclusión}

Puede afirmarse, a modo de resumen, que la concepción que se tiene de la primera niñez entre este grupo de jardineros corresponde bastante bien a su apreciación de la hosca y violenta realidad en que viven los niños de los chircales. Ellos han vivido experiencias traumáticas para su edad, incluyendo la cultura represiva y la discriminación social de que han sido objeto por sus propios padres y familiares, y por los habitantes no chircaleros que rodean a esta comunidad. Los niños chircaleros son rechazados y señalados como de condición inferior; han vivido sometidos dentro de la estructura jerárquica de la familia chircalera que es a la vez una manifestación de las relaciones de dominación propias de la sociedad colombiana, y más aún de sus regiones campesinas atrasadas como las de Boyacá, de donde proviene la mayor parte de las familias chircaleras.

Es sorprendente, y también muy positivo, el constatar que entre los jardineros se ha desarrollado una contraconcepción sobre el niño en relación con la concepción que se tiene de él entre las familias chircaleras. Se insiste entonces en la capacidad que tiene el niño de expresarse, de desarrollar su creatividad, de ser autónomo, de impulsar su imaginación. Se reconoce el valor de la personalidad de cada niño, se reconocen los logros - pequeños o grandes - de cada uno, el niño recibe estímulos, se le permite entrar en relaciones informales, incluso de amistad, con todo el personal del Hogar Infantil, hasta se le convierte en "educador" de los educadores, se insiste en relaciones de igualdad y respeto mutuo, y se le prepara así para que logre una incorporación mayor a la amplia red de relaciones sociales que implica su salida en el futuro de la comunidad chircalera. Predominan en este Hogar Infantil concepciones liberadoras acerca de la niñez que se reflejan claramente en las prácticas pedagógicas allí observadas, tema que será objeto de un próximo artículo.

\section{Los barrios aledaños al Hogar Infantil "La Picota"88}

El Hogar Infantil "La Picota" se ubica en el barrio Palermo Sur, y los niños provienen de este barrio, de la urbanización Diana Turbay, del barrio San Agustín y del barrio La Fiscala.

El barrio de mayor antigüedad es el último, la Fiscala, se origina hace unos 30 años en la venta de terrenos de la antigua hacienda del mismo nombre. Existen, según censo tomado por el Centro de Salud del barrio San Agustín, 435 viviendas (en 1982) e igual número de familias. Se trata de casas muy modestas, de gente pobre, donde los hombres trabajan como obreros, conductores, artesanos en su mayoría, y en donde el trabajo de la mujer fuera del hogar no es muy frecuente. Las familias tienen un promedio de alrededor de 5 o 6 hijos. Todavía hay algunos chircales (hay unas 20 familias chircaleras) que sin embargo, tienden a desaparecer, tanto en razón del agotamiento de la materia prima, como por la cercanía de la empresa ladrillera Santa $\mathrm{Fe}$, que absorbe la producción ladrillera con relaciones sociales de producción de tipo capitalista. El barrio La Fiscala continúa siendo un sector de la ciudad con características un tanto rurales; la mayoría de

\footnotetext{
${ }^{88}$ Tanto el nuevo director de Fe y Alegría como la nueva directora del Hogar La Picota han demostrado tener orientaciones pedagógicas diferentes a las de sus antecesores.
} 
las familias son propietarias de su vivienda y no existen inquilinatos. La comunidad cuenta con una escuela primaria para 350 alumnos en dos jornadas laborales, y un colegio de bachillerato distrital que tiene 250 alumnos en I y II años. Como en varios de los barrios vecinos, existe un gran número de perros, problema que se presenta con especial gravedad en el barrio Diana Turbay ("hay más perros que niños" nos dice la médica del Centro de Salud), lo cual causa un alto número de tratamientos antirrábicos en este (de 7 a 8 por semana). Tanto los maestros como las promotoras y el personal del Centro de Salud demuestran verdadero interés en el bienestar de la población.

Las informaciones sobre ésta indican que la mayoría proviene de trabajadores de la hacienda, aunque hay algunas familias migrantes de otros sectores de Bogotá, y de fuera de la ciudad.

El barrio San Agustín también formó parte de la antigua hacienda de Los Molinos; en éste hay aproximadamente 257 viviendas, según el censo del Centro de Salud, pero se ha extendido en forma alarmante el inquilinato. En cada vivienda hay por lo menos 4 familias, o sea que alrededor de mil familias ocupan esas viviendas, con un promedio de niños que el personal del Centro ubica entre 4 y 6 . La proporción de madres solteras, según la misma fuente es de alrededor de 60 a 70 por ciento, lo que causa graves problemas en cuanto al abandono de los niños quienes permanecen en las calles o encerrados, mientras sus madres salen a trabajar como empleadas domésticas.

El barrio cuenta con todos los servicios públicos, logrados en buena parte por los esfuerzos de la Junta de Acción Comunal. Existe un problema de droga entre los jóvenes que se ha venido acentuando aceleradamente. Hay algunos universitarios entre los jóvenes, lo que distingue a este barrio de sus vecinos, caracterizados por niveles de educación inferiores'

El barrio Palermo Sur empezó a poblarse en forma muy acelerada a partir de 1973, cuando tres o cuatro propietarios de los terrenos decidieron parcelar para la venta.

Palermo Sur no formó nunca parte de la Hacienda Los Molinos, como otros de los barrios de este sector. Hasta julio de 1982 el censo del Centro de Salud mostraba que había 444 viviendas; la población se estima entre 2.500 y 3.000 personas, se calcula que hay alrededor de 1.500 niños menores de 14 años. La mayoría de los hombres trabajan como obreros de la construcción, albañiles, carpinteros, chóferes, etc., mientras que muchas de las mujeres se emplean en el servicio doméstico por días. Los jóvenes en su mayoría asisten a la escuela primaria y secundaria; en el barrio hay una concentración escolar de primaria con capacidad para un poco más de 300 alumnos, en dos jornadas laborales.

Las diversas juntas de Acción Comunal han logrado para la mayor parte del barrio los servicios de agua potable y luz; todavía no existe alcantarillado. Se trata pues de una población de bajos ingresos y de condiciones de vida muy deficitarias.

El barrio cuenta con transporte público que en estos últimos meses se ha visto un tanto incrementado con buses sin subsidio estatal.

El barrio Diana Turbay comenzó a construirse en 1981 y es conocido por tratarse de una urbanización pirata comandada por un ex-concejal de Bogotá y representante al Congreso, quien compró los terrenos, antes potreros, a los hermanos Morales Gómez, dueños de la antigua Hacienda de Los Molinos. Como aún quedaban algunas familias 
chircaleras en estos terrenos, unas 10 apenas, los Morales les dieron estos lotes en pago a las familias correspondientes. El mismo dueño quien también es el gerente de la Cooperativa de Vivienda Popular del Sur oriente, empezó a vender los lotes a $20 \mathrm{mii}$ pesos, y al cabo de pocos meses su precio lo había elevado a $\$ 95$ mil, y aún se vendieron algunos lotes por $\$ 120$ mil. De toda la ciudad acudieron cerca de 7 mil familias que en dos años se han aumentado a unas $8 \mathrm{mil}$, con promedios de 4 a 5 niños por familia. Casi todos los habitantes tienen la propiedad de su lote o casa-lote, siendo en su mayoría obreros, artesanos, trabajadores de oficios manuales varios, miembros de la policía, etc. Hay unos pocos inquilinatos en este barrio, pero el número de habitantes bien puede calcularse alrededor de 50 mil.

En el Diana Turbay hay dos "colegios" particulares, el uno con 360 alumnos en primaria, funcionando en pésimas instalaciones, donde cada alumno paga una pensión mensual de \$370; el otro de kínder y primer año con 80 niños. Las mujeres trabajan en gran parte como empleadas del servicio doméstico por días. Hay algunos lotes sin construir todavía, pero que ya tienen dueño. Ocupa una extensión considerable y no cuenta con ninguna clase de transporte público; después de las 5 p.m. suben unos camperos que cobran $\$ 10$ por persona. Es un terreno pedregoso y montañoso. Los servicios son pirateados, no hay alcantarillado, y en general se trata de una población de bajos recursos económicos. El agua se halla contaminada por las muchísimas conexiones de manguera que hace cada familia, lo cual influye en las deficientes condiciones de salubridad.

\section{La definición social de la niñez entre las jardineras del Hogar Infantil "La Picota”}

Cabe destacar que el hogar Infantil "La Picota" ubicado en el barrio Palermo Sur, es administrado por la Fundación Fe y Alegría, dirigida por un sacerdote jesuita y que incluye colaboradores de diversas comunidades religiosas en todo el país. La directora del hogar, la hermana Dorotea, fue nombrada hace nueve años y remplazada en agosto de 1983; supo imprimirle al proceso educativo un carácter esencialmente represivo y disciplinario, que se manifiesta tanto en las respuestas de las jardineras en las entrevistas que llevamos a cabo con ellas, como en las observaciones del proceso de enseñanza que se llevaron a efecto durante los primeros seis meses de $1983^{89}$.

No es de extrañar que así sea, puesto que la misma hermana asumió la responsabilidad de capacitar parcialmente a las jardineras, mediante cursos dirigidos por ella y exigidos como requisito para ingresar al Hogar Infantil, y por medio de su supervisión permanente de las jardineras. La hermana no pudo dedicarnos el tiempo suficiente para reunir una información más precisa acerca de su propia concepción de la niñez, de los procesos pedagógicos, y de los temas que interesaban en esta investigación. Pero hizo algunas afirmaciones en entrevistas hechas con ella que luego fueron sustentadas por las jardineras.

\section{Orden y disciplina}

Para quien llega por primera vez al Hogar Infantil de La Picota (llamado así por su cercanía con la penitenciaría del mismo nombre), inmediatamente se destacan el orden y la limpieza del edificio y se percibe el ambiente común a tantas casas religiosas, en las que el piso brilla, todo está en su sitio, y reina un silencio sepulcral. No es fácil entender

\footnotetext{
${ }^{89}$ Cf. Salazar, M.C. 'El bienestar del niño y las políticas del estado: los Hogares Infantiles del ICBF en Bogotá' (Informe de avance). Universidad Nacional de Colombia. Bogotá, 1983.
} 
cómo, en este edificio donde reinan el orden y el silencio, se encuentran 300 niños. La hermana atribuye esto al proceso de "educación personalizada" que ella ha fomentado y que consiste en que los niños "aprenden a jugar con el juguete que les corresponde, a sentarse en el puesto que se les asigna, a no molestar, a que no se sientan".

Los niños, en efecto, se ven muy pasivos y existe una impresión de tristeza generalizada en sus rostros y en el ambiente, todo lo contrario de lo que se espera en un lugar escolar infantil. En los salones pueden observar-se grupos de 30 a 40 niños en silencio y casi inmóviles. La hermana insiste en la eficacia de la educación personalizada que ella misma les ha transmitido a las jardineras.

Reflejando la mentalidad autoritaria de la hermana, las jardineras al hablar de los niños con frecuencia repiten la palabra disciplina: "el niño debe ser educado con disciplina", "tiene que aprender a cumplir horarios en forma disciplinada", "debe aprender a seguir un reglamento y a estarse en su lugar". Disciplina que es casi una condenación al silencio y a la inmovilidad, y que además confunde el bien con la inmovilidad y el mal con la actividad, como ya lo señalaba Montessori en los años 20. El niño debe ante todo aprender el respeto a los mayores, así es como podrá adaptarse a su ambiente al convertirse en adulto. El orden es otro de los temas fundamentales para este grupo de educadoras: "hay que enseñar al niño para que aprenda a poner los juguetes en orden", "el niño debe arreglar el salón, poner cada cosa en su sitio, para que en su casa haga lo mismo". Al unísono con estas apreciaciones, se mencionan la rebeldía y la agresividad del niño como sus características sobresalientes, y la hermana señala la necesidad de enseñar terapias especiales a las jardineras para aplicarlas a los niños rebeldes.

Estas formas de pensar se reflejan naturalmente en las actividades que se emprenden con los niños y en el trato de que son objeto. Por ejemplo, no se llama a los niños por su nombre, sino que se les asignan números en los distintos salones. La jardinera se dirige a ellos por el número asignado, rara vez por el nombre; y los mismos niños se llaman el uno al otro por los números! Al niño se le reprime permanentemente: que se calle, que no se mueva, que haga silencio, que no mire para afuera. Todo lo debe saber hacer a la hora que corresponde, hasta sus necesidades fisiológicas. De lo contrario se expresa disgusto, desaprobación. Se enfatiza la auto-restricción y un sentido estricto del deber: se debe hacer lo que se nos dice que hagamos, la autoridad tiene siempre la razón. El niño no tiene libertad para determinar lo que va a hacer, se le presentan pocas oportunidades de escogencia entre una y otra actividad o juego. Todo está pre-determinado para él.

Esta misma orientación impide a las jardineras plantearse reflexiones sobre la independencia, la libertad, la creatividad del niño. Estos conceptos no aparecieron en las entrevistas, ni otros elementos de lo que constituiría una tendencia liberadora en la educación, como la utilidad del juego en el aprendizaje de los niños. Más bien, las jardineras le dan mucha importancia al concepto del "trabajo" del niño. Se dice que el niño está "trabajando" cuando está desarrollando actividades en los salones de clases, aunque en algunos casos se trate de juegos. Para las jardineras, el juego sólo se da cuando los niños salen al recreo; así, si una niña juega con una muñeca durante el llamado "trabajo libre", esa niña está "trabajando", es decir, según las jardineras, "el niño está pensando cuando trabaja, y sólo cuando trabaja, en el juego no es lo mismo, porque no está desarrollando su inteligencia".

Por lo menos las jardineras encuentran, a pesar de ésta orientación represiva, que a los niños les gusta aprender y que les llama la atención casi cualquier actividad que la jardinera les indique: escribir, pintar, dibujar, pegar y cortar papeles. Pero insisten en que 
hay que corregir al niño: "el niño pinta una cara de morado, y hay que decirle que eso está mal, que la cara tiene otro color"; "a los niños hay que darles las hojas de dibujo prediseñadas" porque "no saben dibujar bien", y comentarios diversos que excluyen la autodeterminación del niño, su capacidad de determinar por sí mismo lo que hace.

\section{Relaciones entre los niños y sus padres}

A pesar de que las jardineras tienen poco trato con las familias de los niños, es posible afirmar que ellas conocen las condiciones en que viven por pertenecer a los mismos barrios de donde provienen los niños. Por experiencia propia ellas conocen que en estos barrios faltan las redes de alcantarillado, que el agua no es siempre potable, que los niños toman agua sucia y juegan en el barro, que provienen de familias muy pobres que no pueden alimentarlos en forma adecuada. Pero las jardineras tienden a negar este origen similar al de las familias de los niños, como se desprende de algunas de sus apreciaciones. Este rechazo conduce en ellas a una subvaloración de las madres de familia que raya un poco en el desprecio de las mismas y que conduce a una noidentificación con ellas. También puede interpretarse esta situación como un resentimiento que existe en las jardineras por las tareas que ellas cumplen y que constituyen un reemplazo de las madres. Las jardineras, por ejemplo, se refieren a que "las madres dejan a sus niños en el Hogar Infantil, sólo por deshacerse de ellos". Expresan que las madres desconocen las tareas llevadas a cabo por las jardineras: "ellas creen que no hacemos nada en todo el día, que los niños aquí sólo juegan”. Pero desconocen que el Hogar Infantil es muy bueno para los niños, que ellos vienen es para aprender, y que día por día los niños aprenderán más. Muchas mamás piensan que no, que estamos es pasando el tiempo sin trabajar, con las manos cruzadas.

Las jardineras observan también que entre las madres falta afecto por el niño. Esto se debe, a su juicio, en parte a la carga excesiva de trabajo que tiene que asumir la mujer de estos barrios. Es ella la única responsable de la crianza de los niños y de los oficios domésticos; el hombre rara vez aparece por el Hogar Infantil; de allí que la mujer tenga que acudir a los niños para toda clase de oficios. Esto explica también la poca comunicación existente entre padres e hijos; cerca del 50 por ciento de los niños no tienen a su padre viviendo con ellos, y casi el 90 por ciento de las madres trabajan como empleadas en el servicio doméstico, en jornadas largas que se prolongan aún más por las distancias que deben recorrer al ir y venir del trabajo.

Por estas razones las relaciones entre padres e hijos son deficientes, e igualmente entre padres y jardineras. No parece existir en este Hogar una política encaminada a lograr la continuidad del proceso educativo entre los padres de familia, a pesar de múltiples declaraciones y documentos al respecto por parte del Instituto Colombiano de Bienestar Familiar.

Las jardineras se refieren a los aspectos de madurez precoz que a veces presentan los niños de estos barrios atendidos por el Hogar Infantil. Los niños cuentan historias trágicas que han presenciado o vivido: casos de padres borrachos, de intervención de policías y patrullas, de violencia contra la mujer y contra los niños, que por lo general dejan traumatismos profundos en los niños. Hay niños que permanecen meses enteros repi. tiendo algunas de esas historias; niñas que cuentan que su mamá ha sido amenazada por un hombre con armas punzantes, o que describen la represión permanente y el castigo violento que se les inflige. 
Hay niños que reflejan temor al llegar al Hogar Infantil, temor ante los adultos e incluso frente a otros niños; las jardineras creen que esto corresponde a los castigos que reciben los niños en sus casas, muy frecuentes, y que incluyen golpes, sumergidas en agua fría a medianoche, encierro. Castigos que se les imponen por motivos totalmente insignificantes, sin razón alguna. Quizá por esos choques permanentes con la realidad cotidiana de los niños, éstos tienden a ser como adultos. Dice una jardinera, "uno quisiera que el niño pudiera vivir y soñar su infancia de manera diferente". Pero al niño de estos sectores le toca enfrentarse con la dureza de la vida desde muy pequeño. Se desarrolla en él una sensibilidad especial, por ejemplo, al ver el sufrimiento que soporta su madre. Los niños al hablar de los problemas de sus madres revelan unos sentimientos que están más allá de su edad. Esa madurez, ese ser adulto mientras se es niño, es también responsabilidad de los adultos que rodean al niño. Dice una jardinera:

Nosotras mismas, como muchos adultos, somos las responsables de esa maduración precoz de los niños, les otorgamos responsabilidades que están más allá de su edad, como la de cuidar a los niños más pequeños de la casa. Y a las niñas en especial, las ponemos a prender la estufa, lavar, planchar, cocinar, hacer el tinto, arreglar la casa. El niño que es un poco grandecito tiene que hacer de todo, cuidar carros, cuidar la casa, mirar por esto y por aquello, y todo eso hace que el niño madure y actué como adulto. Es también por lo que las mamás no alcanzan a hacerlo todo; ellas necesitan de esa ayuda de los niños, sobre todo cuando no tienen la ayuda del esposo.

Las jardineras se refieren a la represión que las familias ejercen con los niños, aunque se trata de la misma concepción que prevalece en ellas. Pero señalan que entre las familias hay la convicción acerca de la educación como un camino hacia el progreso. Por lo general, los padres de familia, y en especial las madres, desean para sus hijos lo que ellos no pudieron obtener. En primer lugar, educación, que les permita "valerse por sí mismos".

Muchos de los conceptos anteriores señalan el aprecio y el afecto de las jardineras hacia los niños; ellas llegan a quererlos como si fueran sus hijos y comparten sus sufrimientos plenamente.

\section{Resumen}

Puede decirse que este grupo de jardineras demuestra en primer lugar un sentido realista al apreciar al niño como éste se encuentra en las condiciones propias de los barrios Palermo Sur y sus aledaños. Se trata de niños que han sufrido desde pequeños, y cuya infancia se ha visto marcada por traumas y deficiencias severas. Son niños a los cuales se castiga fuertemente, hasta con crueldad inexplicable para el observador de fuera, pero que quizá puede explicarse como parte de la violencia estructural de esta sociedad. Son niños que actúan como adultos, que asumen responsabilidades que no debieran corresponderles por su edad, pero que los adultos imponen sobre ellos; son niños que han sido reprimidos en múltiples formas y que por eso mismo se muestran tímidos, inseguros, temerosos, con dificultad para expresarse. Son niños en cierto modo convertidos en adultos, que expresan sentimientos y una sensibilidad que sorprende. Son niños --como lo expresara bellamente una jardinera- que no pueden soñar ni vivir su infancia en libertad, por las condiciones sociales en que tienen que vivir. Muchas veces estos niños se convierten en estorbo para las personas mayores que los rodean; por ello se les exige pasividad, silencio, inmovilidad. 
Dada la estructura autoritaria de este Hogar Infantil, por lo menos hasta agosto de 1983, a las jardineras no se les había dado oportunidad de reflexionar sobre las mismas metodologías pedagógicas que se imponen a los niños. Su práctica en educación preescolar es empírica; muchas de las jardineras son autodidactas si se quiere, y conocen poco acerca de las diferentes teorías sobre el desarrollo del niño. Se aplican los criterios de disciplina, orden, atención, impuestos por la antigua directora. Reflejo de métodos tradicionales, todo ello reposa en la concepción de que el niño debe desarrollarse dentro de la inmovilidad y el silencio, y sobre la extraña idea de que el niño debe mantenerse en una posición determinada para que se beneficie de la educación. Así es como aprenderá a "estar en su puesto", pero precisamente, como ya lo señalaba Montessori en la década de los años 20, la inmovilidad y el silenció impiden que el niño se desarrolle.

\section{BIBLIOGRAFIA CITADA}

CENAC, Camacol, Colciencias. DAPD. Diagnóstico del estado económico y tecnológico de la industria ladrillera en el país. Bogotá. 1976.

CHAMBOREDON, J. C. y J. Prévot. Changes in the Social Definition of Childhood. Theory an Society, III, 2: 331-350.

DOHM, H. Die Arbeitsteilung zuischen Mann und Frau, en Brinaer Gabler, C. (ed.). Frauenarbeit und Beruf. 1979. Fiseher, Frankfurt, 1874,

MONTESSORI, M. L'enfant. París, 1923.

MONTESSORI, M. L'enfant. París, 1923. Pedagogie Scientifique. La découverte de l'enfant. París, 1952.

SALAZAR, M.C. El bienestar del niño y las políticas del Estado: jos Hogares Infantiles del ICBF en Bogotá (Informe de avance). Universidad Nacional de Colombia. Bogotá, 1983.

VELASQUEZ, F. y P. VILA. El proceso productivo en los chircales de Bogotá. DAPD. Bogotá, 1974.

ZAMUDIO, I. y H. CLAVIJO. El barrio popular: marginados o ejército industrial de reserva? Controversia, CINEP. Bogotá, 1983.

SUMARIO: Este artículo ofrece algunos de los resultados obtenidos en el desarrollo de una investigación sobre la educación pre-escolar en el sur de Bogotá. Se trata de estudios de caso realizados en tres hogares infantiles del Instituto Colombiano de Bienestar Familiar y ejemplifica las concepciones de la niñez que tienen los jardineros que trabajan en ellos.

DESCRIPTORES: Educación del niño, infancia, investigación educacional, metodología de la investigación, Colombia. 